\title{
Comparison between Impulse and Holographic Subsurface Radar for NDT of Space Vehicle Structural Materials
}

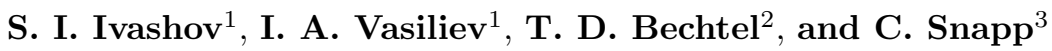 \\ ${ }^{1}$ Remote Sensing Laboratory, Bauman Moscow State Technical University, Russia \\ ${ }^{2}$ Enviroscan, Inc./University of Pennsylvania, USA \\ ${ }^{3}$ NASA Johnson Space Center, USA
}

\begin{abstract}
A subsurface holographic radar using a multi-frequency signal has been developed for inspecting dielectric construction materials. The characteristic feature of this device is the ability to obtain one-sided radar soundings/images with a high sensitivity and high resolution $(2 \mathrm{~cm})$ in the frequency band of 3.6-4.0 GHz. One promising application of the device is nondestructive evaluation of the heat protection system and other materials on the U.S. Space Shuttle, and proposed crewed exploration vehicle (CEV). The advantages of this continuouswave holographic radar over traditional impulse subsurface radars are discussed and illustrated by experimental results.
\end{abstract}

The disastrous loss of the space shuttle Columbia, as well as even more recent dangerous incidents that were thankfully resolved, have aroused interest in possible new methods and devices for nondestructive testing and evaluation of the Space Shuttle Thermal Protection System, the external fuel tank insulating foam, and other materials and structures on the shuttle (see Figure 1), proposed $\mathrm{CEV}$, and other space vehicles. Voids in or under the external tank insulating foam are considered potential sites for "cryopumping" where water seeps in and then evaporates explosively at altitude, pulling the foam from the tank (Figure 2).

One of the possible means for non-destructive testing (NDT) and evaluation of structural materials is subsurface radar. This method is based on the propensity of electromagnetic waves to be reflected at permittivity contrasts. Up to now, the use of radar for NDT has been hindered by

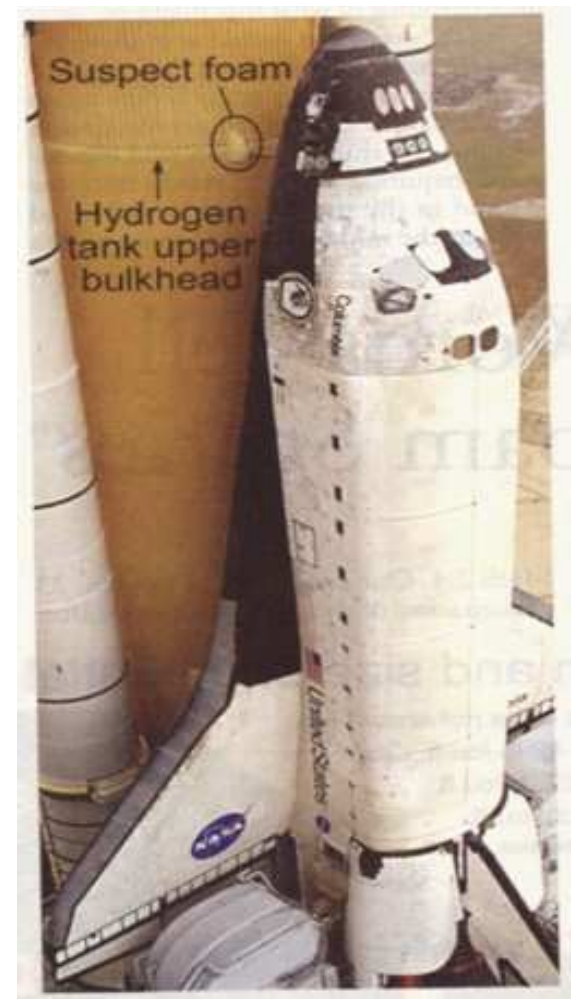

Figure 1: Suspect flaws on the external hydrogen tank coating [1].

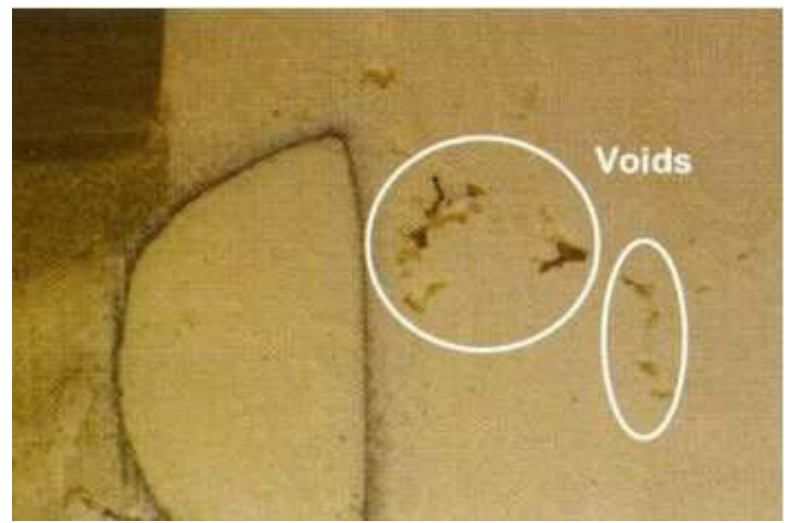

Figure 2: Close-up of voids in the external tank insulating foam $[2]$. 
insufficient resolution of available subsurface radars. For many important practical NDT problems, it is sufficient to have a sounding depth in the range of 10 to 20 centimeters $(\mathrm{cm})$, but the spatial resolution should be not less than 2 to $3 \mathrm{~cm}$ - beyond the abilities of conventional impulse radar systems. However, taking into account the small required sounding depths, it is possible to use a continuous wave (as opposed to impulse), multifrequency radar signal. This device is reflection mode radar (i. e., the transmitting and receiving parts of the antenna are located on the same side of the sounded surface), however the subsurface images are generated as a plan-view holograph rather than as travel time cross-sections as in impulse radar (Figure 3). The holographic radar system operates in frequency range of 3.6 through $4.0 \mathrm{GHz}$, and uses 5 working frequencies at two receiver polarizations each $[3,4]$.

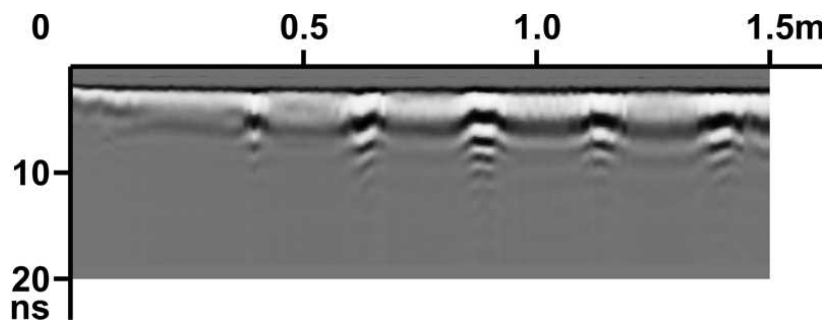

Figure 3: Impulse radar image of spaced metal rebar in a concrete airstrip.

At shallow depths, holographic radar has a distinct advantage in resolution over impulse radar because the radar frequency range can be easily adapted to the demands of a particular NDT task. Another extremely important advantage of this holographic radar technology is the possibility that it can image, without reverberation, dielectric materials that lie above a metal surface. Such materials cannot currently be inspected non-destructively with traditional time-domain impulse radar technology.

For example, Figure 3 depicts an impulse radar cross-section of a reinforced concrete airstrip [5]. Reverberation of pulses between the radar antenna and shallow metal objects obscures the actual location and shape of the reinforcing bars (rebar) which are seen as multiple reflections (often called ghosts or phantoms) of the transmitted impulse signal on the relatively uniform background. Furthermore, the reflected pulses characteristically form images that are segments of arcs or parabolas because of a relatively wide antenna-beam pattern (up to $60^{\circ}$ opening angle) of impulse radars.

In this experiment impulse subsurface radar OKO (Logis Ltd, Russia) with central frequency of 1.2 GHz had been used. In Figure 3, the horizontal axis at the image corresponds to distance along the airstrip surface, and the vertical axis corresponds to a time axis, which is related to delay-time

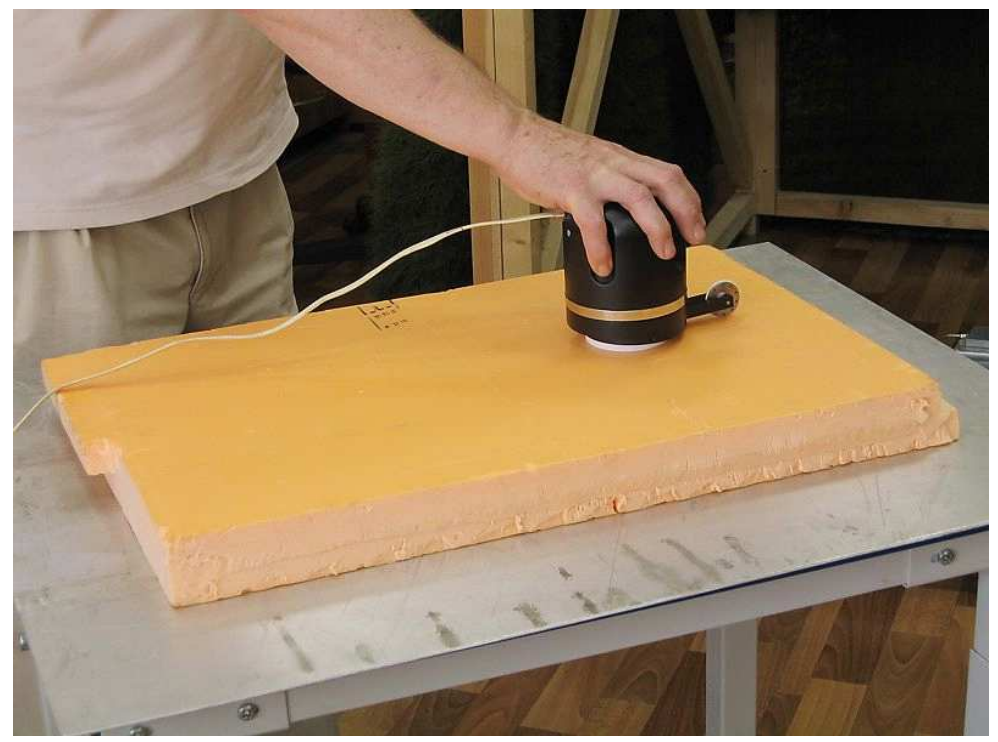

Figure 4: Plastic foam over an aluminum sheet as used for experiments. 
of radar signal.

Laboratory experiments with the holographic radar have been conducted to investigate various types of model flaws or anomalies within a rigid 5 centimeter thick foam plastic board overlying an aluminum sheet (Figure 4). The anomalies consisted of voids in the foam, some of which were water-filled. These known defects were imaged using the holographic radar.

The results of the experiments are presented in Figures 5 and 6. Note that the holographic radar produces plan-view or footprint images of the anomalies. The model defects in and under the foam were wetted to varying degrees. Since water has a permittivity of about 80, even small amounts of moisture produce dramatic defect images. The visible "waviness" in these radar images is due to the holographic nature of the radar.

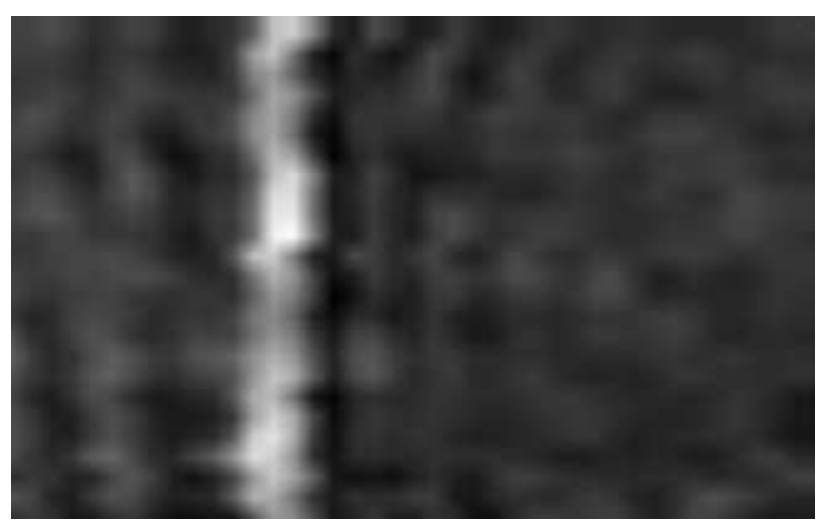

Figure 5: Holographic radar image of a wetted seam in the foam.

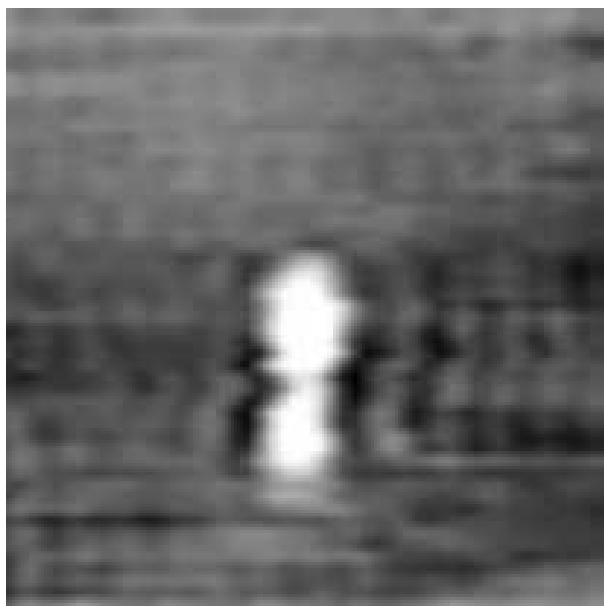

Figure 6: Holographic radar image of a damp cloth between the plastic foam and aluminum sheet.

In addition, preliminary experiments with actual Space Shuttle heat protection tiles and adhesive were performed at the NASA Jet Propulsion Laboratory (Figure 7). Dimensions of the tiles were 6 by 6 inches in plan, with thicknesses of 1 to 2 inches. The purpose of the experiment was to determine whether it is possible to detect different types of de-bonding of the tiles from the underlying aluminum sheet. To accomplish this, parts of the aluminum sheet surface were intentionally left without glue (see Figure 8). In this Figure, two round holes (or holidays in the common parlance of technicians) are evident; \#1 dry, and \#2 with several drops of water. A tile with 2 inch thickness

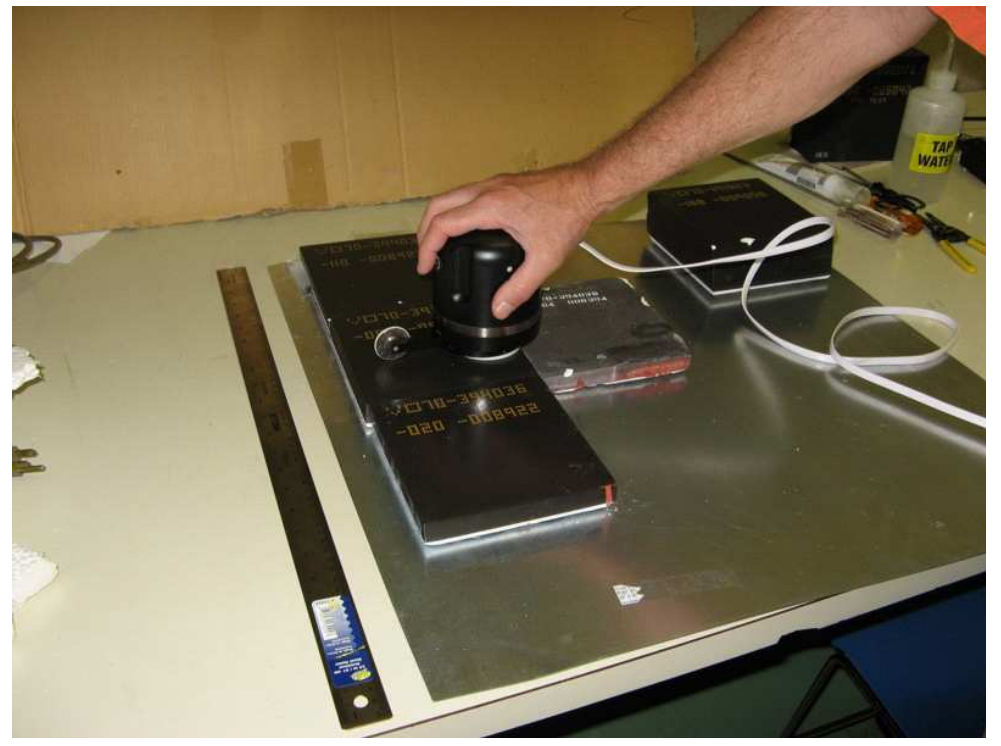

Figure 7: Different types of Space Shuttle tiles that were used in experiments. 
was pressed into the glue, and allowed to cure overnight. Results of subsequent radar scanning of this tile are presented in Figure 9. The water-filled holiday has a dramatic contrast, while the air-filled holiday is more subtle, but still clearly visible. The originally round shapes of the holidays (see Figure 8) have been distorted by pressing the tile into the glue, and the water-filled holiday may appear larger due to seepage of water beyond the original holiday boundary. Although more detailed experiments are needed to understand all of the capabilities of holographic radar for NDT of space vehicle heat protection systems, these initial experiments are extremely promising.

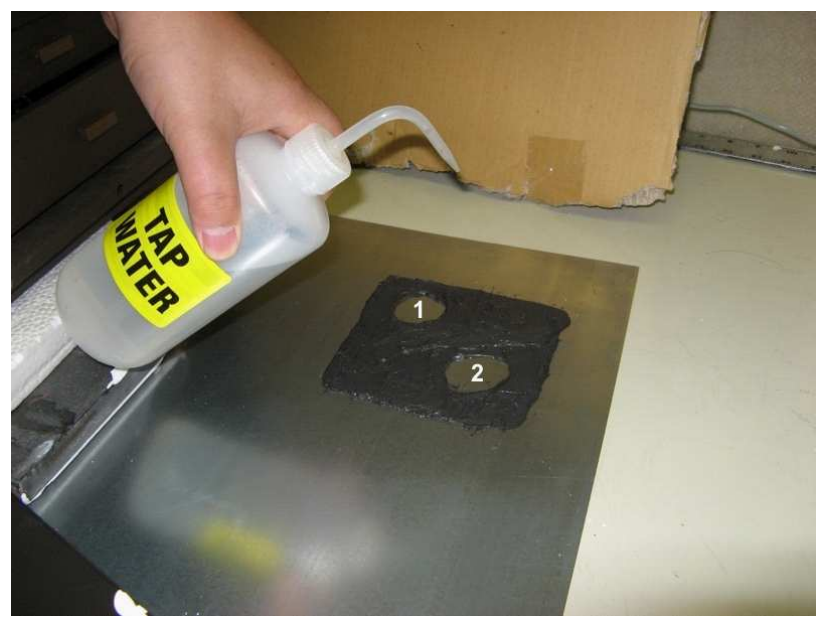

Figure 8: Part of aluminum sheet was covered with glue. Two spots inside were without glue. One of the spots (2) was filled with water.

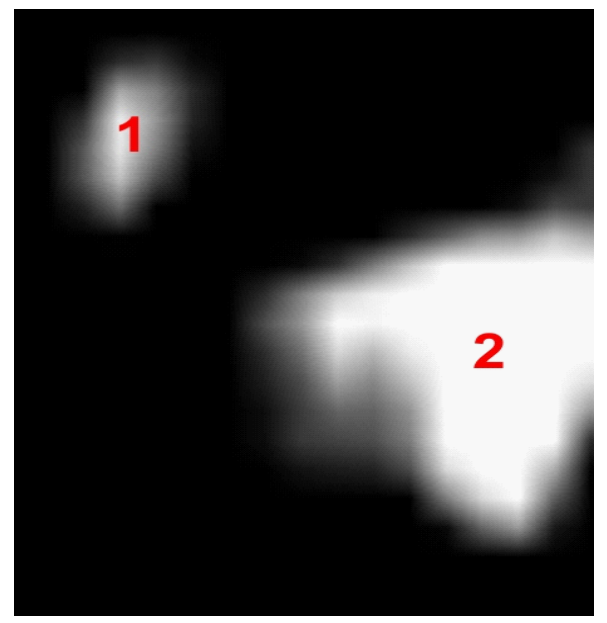

Figure 9: Result of radar scanning of the tile. This tile is visible in right upper corner of Figure 7.

In addition, it is shown that radio-frequency hologram reconstruction allows estimation of the depth of shallowly-buried objects and improves the lateral resolution of images with increasing target depths [6]. Furthermore, for even better resolution of the microwave images, the design of a holographic radar operating at a higher frequency (up to 20 to $30 \mathrm{GHz}$ ) is discussed.

\section{ACKNOWLEDGMENT}

Experiments with Space Shuttle tiles were conducted with the help and active participation of Dr. T. Lu, NASA Jet Propulsion Laboratory, USA.

Support for this work was provided by the International Science and Technology Center.

\section{REFERENCES}

1. Aviation Week \& Space Technology, 28, February 17, 2003.

2. Aviation Week \& Space Technology, 31, April 7, 2003.

3. Vasiliev, I. A., S. I. Ivashov, V. I. Makarenkov, V. N. Sablin, and A. P. Sheyko, "RF band high resolution sounding of building structures and works," IEEE Aerospace \& Electronic Systems Magazine, Vol. 14, No. 5, 25-28, May 1999.

4. Ivashov, S. I., V. V. Razevig, A. P. Sheyko, I. A. Vasilyev, and T. D. Bechtel, "Holographic radar as a tool for non-destructive evaluation of structural materials," Proceedings of the 2005 SEM Annual Conference \& Exposition on Experimental and Applied Mechanics, Portland, Oregon, USA, Tuesday, June 7-Thursday, June 9, 2005.

5. Chapursky, V. V., S. I. Ivashov, V. V. Razevig, A. P. Sheyko, I. A. Vasilyev, V. V. Pomozov, N. P. Semeikin, and D. J. Desmond, "Subsurface radar examination of an airstrip," Proceedings of the 2002 IEEE Conference on Ultra Wideband Systems and Technologies, UWBST'2002, 181-186, Baltimore, Maryland USA, May 20-23, 2002.

6. Chapursky, V. V., S. I. Ivashov, V. V. Razevig, A. P. Sheyko, and I. A. Vasilyev, "Microwave hologram reconstruction for the RASCAN type subsurface radar," Proceedings of the Ninth International Conference on Ground Penetrating Radar, GPR'2002, 520-526, Santa Barbara, California USA, April 29-May 2, 2002. 